\title{
Some Probability Distributions and L-Moment in Hydrological Engineering
}

\author{
Khurshid Ahmad, Bashir Ahmad, Akhtar Alam
}

\begin{abstract}
Extreme hydrological situations constantly disturb the earth activities and life, to envisage such extreme activities we need a system that alarms well on time and recognized the expected danger; to prepare such systems one must have knowledge of the significant factors that are actively responsible for such extreme situations and we should have a reliable statistical technique that helps to prepare a useful model for such systems. In this paper we investigate the historical data of peak flood from several gauging stations of river Jhelum in Kashmir, India. A reliable estimation technique (L-moment) is applied for parametric estimation of the probability distributions and a reliable testing techniques are used to check the accuracy of fitting of the distribution, in additional to that L-moment ratio diagram (LMRD) is used to impart information about fitting of distribution. Log Pearsons-III distribution shows better results and satisfies tests of distribution fitting, same probability distribution is globally accepted for flood forecasting.

Key Words: L-Moments, Jhelum, P-P plot, L-moment ratio diagram, Return period.
\end{abstract}

\section{INTRODUCTION}

Extreme hydrologic situations cause miseries to human beings and earth activities. To identify the trend and the movements of such situations we should have good knowledge of the significant factors involving in system and the reliable statistical techniques, in order to save the human and economic losses, we should build such a system that not only provides the warning before the extreme situation but also support and remain effective in those conditions. As far as the hydrologic forecast and allied constructional/managemental scrutiny is considered one must have the adequate knowledge about the concerning factors that plays vital role and latest statistical techniques that is used to frame better models. Some methodologies are used to make decisions about flood warning response, flood warning zones $[8,10]$, optimal decisions are taken for hydrological forecasting based on the adequate information and efficient models $[2,9,12]$.

Different researchers suggest that a good number of probability distributions are used for flood frequency analysis $[5,7]$. Mostly the probability distributions that are used in flood frequency distributions are extreme value Type -I, Generalized Pareto distribution, Log Pearson-III, Generalized extreme value distribution and normal distribution [3].

Revised Manuscript Received on June 15, 2020.

* Correspondence Author

Dr. Khurshid Ahmad Bhat*, Senior Lecture, Department of Education $\mathrm{J} \& \mathrm{~K}$, India

Dr. Bashir Ahmad, Lecture, Department of Education J\&K, India.

Dr. Akhter Alam, Assistant Professor, Department of Geography, University of Kashmir, India.

(C) The Authors. Published by Blue Eyes Intelligence Engineering and Sciences Publication (BEIESP). This is an open access article under the CC BY-NC-ND license (http://creativecommons.org/licenses/by-nc-nd/4.0/)
Parametric estimation in these distributions are mostly done by using method of moments, in this method assessing to higher moments becomes very difficult and this method is considered as less accurate comparative to other methods, to overcome such shortcomings L-moment method (LM) provides better results [4], Kumar, Saf and Yue used the Lmoment methods for estimations of parameters of probability distributions [11,13,16].

In the valley of Kashmir river Jehlum is the main source of hydrological extremes, flows through the region from south to north and entered into Pakistan (figure-I), we have investigate the instrumental data of peak flood of 58 years of this region from the different gauging stations, Sangum in south Kashmir, Ram-Munshibagh in central Kashmir and Asham in north Kashmir.

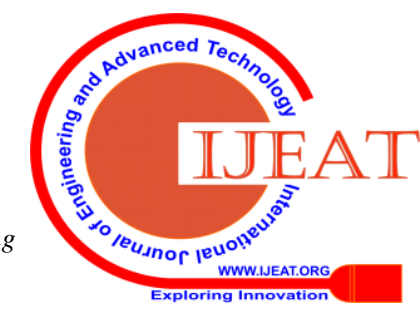




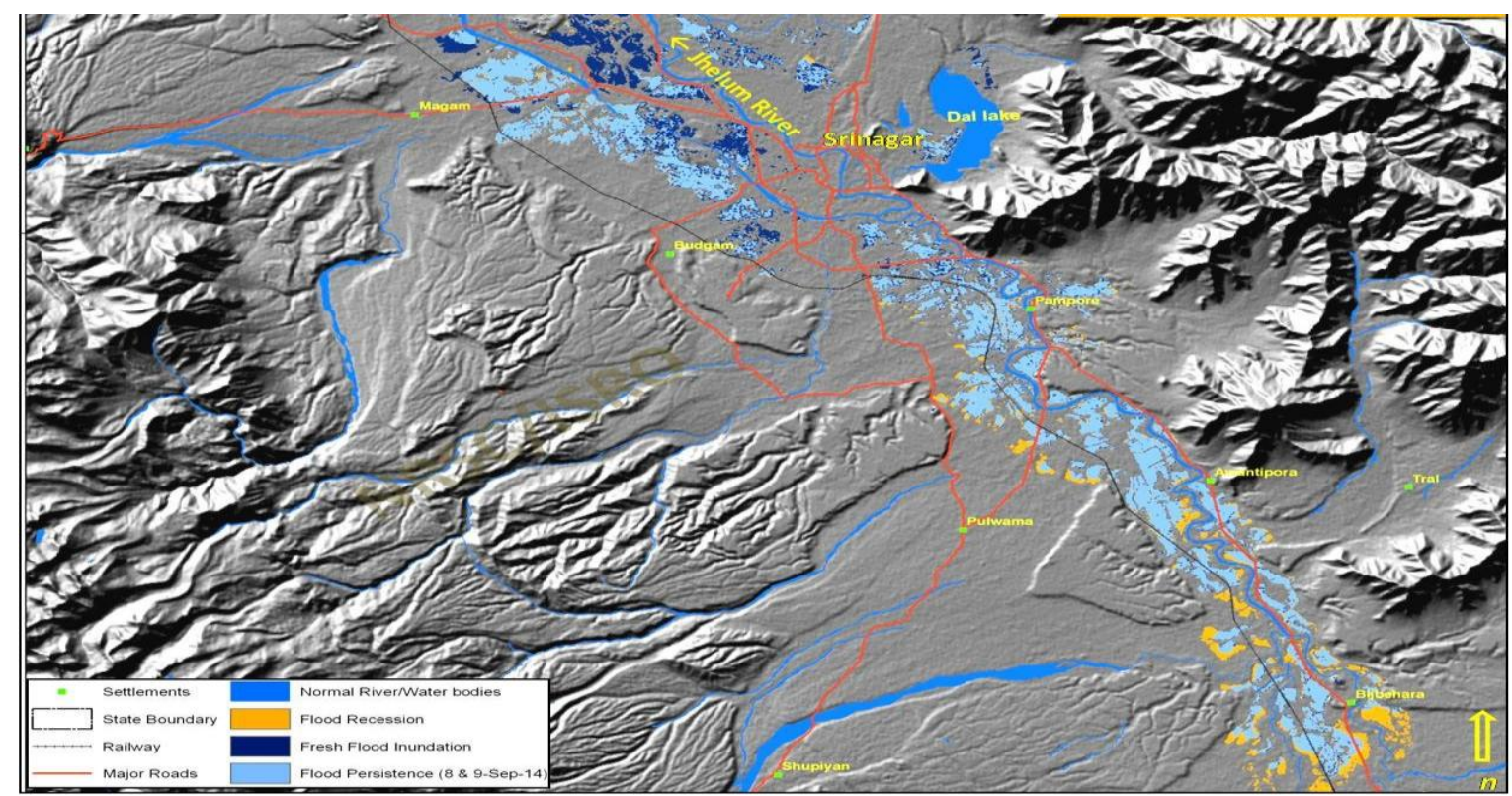

Fig. I. Ariel view of River Jhelum

\section{METHOD}

L-moments(LM) are linear functions of ordered statistics having less biasing, less effected by sampling variability and are more robust than conventional moments $[4,15]$. The Lmoments for the order statistics is:

$$
\lambda_{r}=I / r \sum_{k=0}^{r-1}(-1)^{k}\left(\begin{array}{c}
r-1 \\
k
\end{array}\right) E\left(X_{r-k: r}\right)
$$

Three probability distributions are used, two of them are three parametric (GEV and LP3) and one is two parametric (Gumbel). The aptness of the distributions is investigated by various tests like Kolmogorov-Smirnov (KS), AndersonDarling (AD), and the Chi-Squared.

\subsection{Generalized Extreme Values (GEV)}

Generalized extreme value distribution is the combination of Weibull, Gumbel and Frechet probability distributions, it has three parameters: location parameter (z), scale parameter $(\alpha)$ and shape parameter $(k)$. Probability distributions having more number of parameters will be considered as more efficient specially in hydrological engineering [6], even two parametric distributions sometimes have good results but in case of small sample size [1].

\subsection{Log Pearson Type- III Distribution (LP3)}

Similar to GEV, log pearson Tpe-III also uses three parameters: location parameter $(\mu)$, scale parameter $(\sigma)$ and shape parameter $(\gamma)$, it belongs to the family of pearson type-III.

\subsection{Gumbel Distribution (EV1)}

Gumbel distribution is a two parametric distribution, location parameter $(z)$ and scale parameter $(\alpha)$. Standard error of two parametric distributions like (EV1) are smaller but biasing is large as compared to 3 or 4 parametric distributions [1].

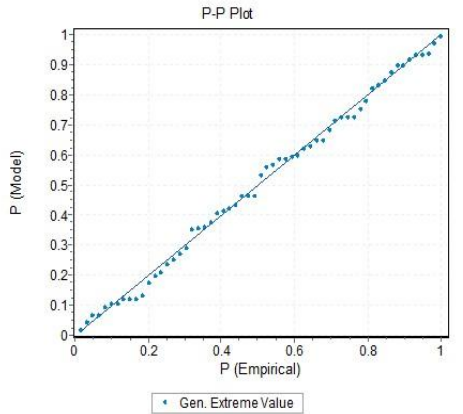

(a)

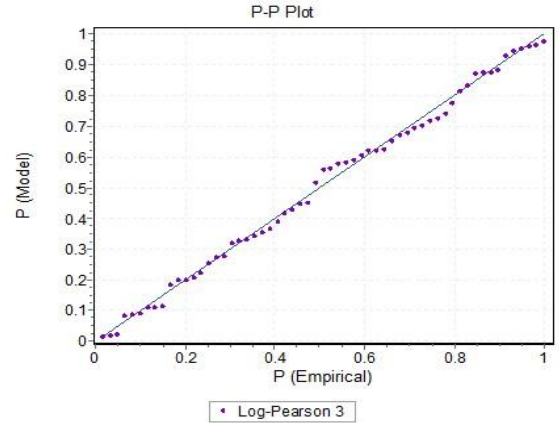

(b)

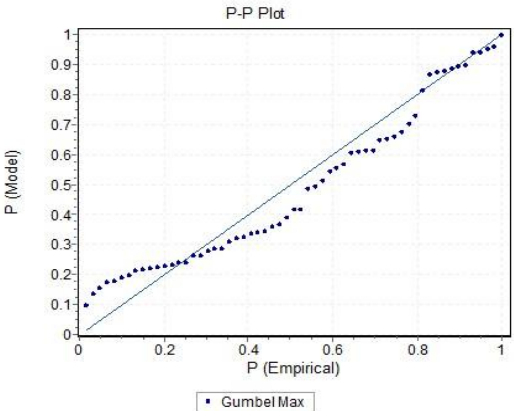

(c)

Fig. II. (P-P plot of three stations)

III.

\section{GOODNESS OF FIT TESTS}

Various tests (parametric and non-parametric) are used to check the efficient fitting of probability distribution to the given data, in these tests, test \& Sciences Publication statistics are calculated and analyzed. Here we use nonparametric tests like Kolmogorov-Smirnov, Chi-Square and Anderson-Darling [14].

(C) Copyright: All rights reserved.

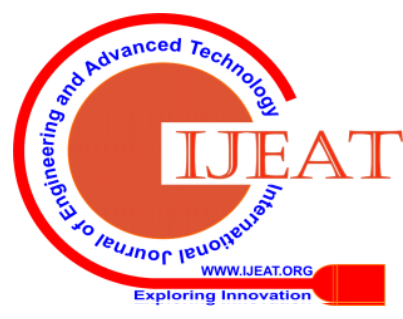


Table I

\begin{tabular}{|c|c|c|c|c|c|c|c|}
\hline \multirow[t]{2}{*}{ Station } & \multirow[t]{2}{*}{ Distributions } & \multirow{2}{*}{$\begin{array}{l}\text { Sample } \\
\text { Size }\end{array}$} & \multicolumn{2}{|c|}{ Kolmogorov-Smirnov } & \multicolumn{2}{|c|}{ Chi-Square } & \multirow{2}{*}{$\begin{array}{c}\begin{array}{c}\text { Anderson- } \\
\text { Darling }\end{array} \\
\text { Statistics } \\
\end{array}$} \\
\hline & & & Statistics & p-Value & Statistics & $p$-Value & \\
\hline \multirow{3}{*}{$\begin{array}{c}\text { I } \\
\text { Sangum }\end{array}$} & $\begin{array}{l}\text { Generalized } \\
\text { Extreme } \\
\text { Value }\end{array}$ & 59 & 0.06857 & 0.90131 & 2.9735 & 0.70213 & 0.2228 \\
\hline & Log-Pearson III & 59 & 0.0716 & 0.9010 & 2.376 & 0.795 & 0.22142 \\
\hline & Gumbel & 59 & 0.1239 & 0.1239 & 4.884 & 0.299 & 0.42365 \\
\hline \multirow{3}{*}{$\begin{array}{c}\text { II } \\
\text { Ram MunshiBagh }\end{array}$} & $\begin{array}{c}\text { Generalized } \\
\text { Extreme } \\
\text { Value } \\
\end{array}$ & 59 & 0.0548 & 0.99023 & 2.3259 & 0.80245 & 0.1625 \\
\hline & Log-Pearson III & 59 & 0.05429 & 0.99122 & 1.2423 & 0.94076 & 0.1531 \\
\hline & Gumbel & 59 & 0.05516 & 0.98948 & 2.3142 & 0.80419 & 0.16677 \\
\hline \multirow{3}{*}{$\begin{array}{c}\text { III } \\
\text { Asham }\end{array}$} & $\begin{array}{l}\text { Generalized } \\
\text { Extreme } \\
\text { Value }\end{array}$ & 59 & 0.05892 & 0.97913 & 2.6497 & 0.75381 & 0.19416 \\
\hline & Log-Pearson III & 59 & 0.06357 & 0.95869 & 0.903 & 0.97 & 0.18036 \\
\hline & Gumbel & 59 & 0.07675 & 0.85148 & 1.143 & 0.95022 & 0.3523 \\
\hline
\end{tabular}

IV.

\section{L-MOMENT RATIO DIAGRAM (LMRD)}

An additional mode to check the fitting of distributions is the (LMRD), it the diagram which represents the relationship between L-Skewness and L-
Kurtosis $(\tau 3, \tau 4)$ of data plotted against points and constant lines. Actually LMR Diagram is the visual check of the necessary fitting of the distribution.

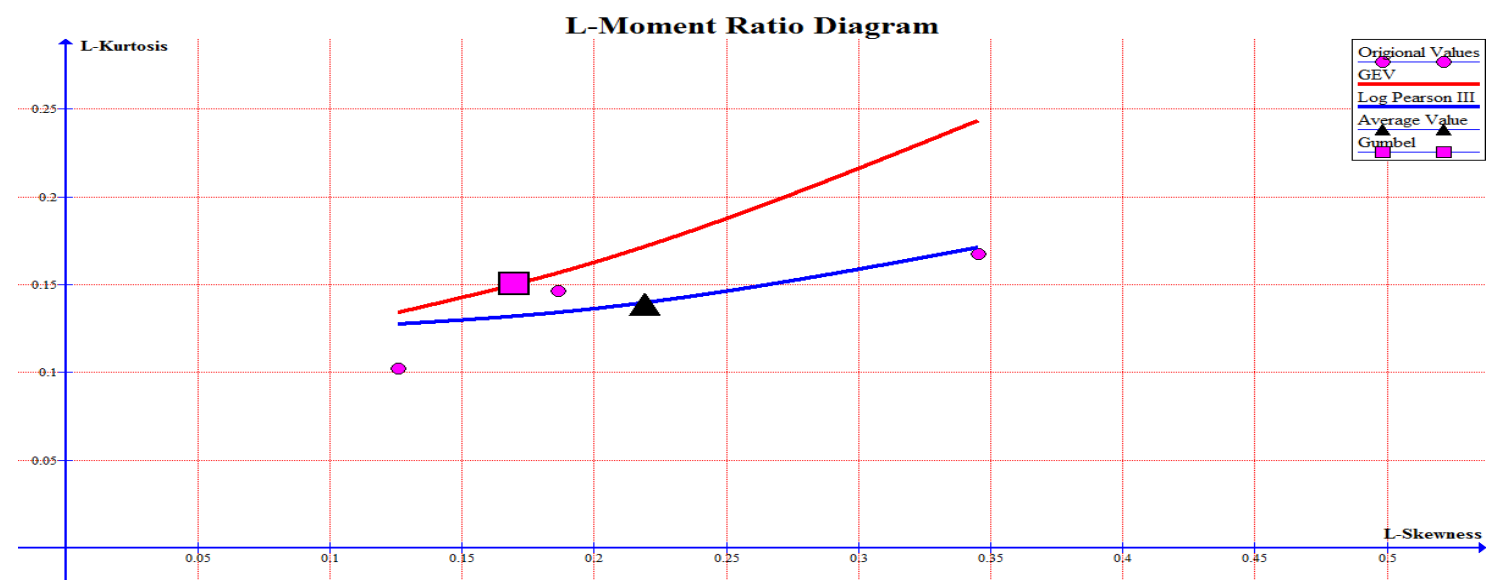

Fig. III. L-Moment Ratio Diagram

\section{RETURN PERIOD}

The return period (year) of three gauging stations using Log Pearson's probability distributions (LP3) is given in Table II,
Published By:

Blue Eyes Intelligence Engineering

\& Sciences Publication

(C) Copyright: All rights reserved. 


\section{Some Probability Distributions and L-Moment in Hydrological Engineering}

Table II

\begin{tabular}{|c|c|c|c|}
\hline $\begin{array}{c}\text { Return Period } \\
\text { (Year) }\end{array}$ & Station I (Sangum) & $\begin{array}{c}\text { Station II } \\
\text { (Ram-MunshiBagh) }\end{array}$ & Station III (Asham) \\
\hline 2 & 549.54 & 602.55 & 732.34 \\
\hline 5 & 1000.00 & 977.24 & 1114.36 \\
\hline 10 & 1348.96 & 1174.89 & 1344.61 \\
\hline 25 & 1819.70 & 1479.11 & 1606.69 \\
\hline 50 & 2137.96 & 1698.24 & 1781.77 \\
\hline 100 & 2511.88 & 1862.08 & 1940.90 \\
\hline 200 & 2884.03 & 2041.74 & 2086.54 \\
\hline
\end{tabular}

\section{CONCLUSION}

L-moment method provides better estimation with less biasing of unknown parameters of important probability distributions using in hydrological system, throughout the world it is a main requirement that how to judge the trends of extreme hydrological situation, so that we can reduce economical and human losses. Knowing the key factors involving the system and using the proper statistical techniques we may be able to establish a reliable system that predicts and monitor the situations. Here we see that the Log Pearsons-3 distribution shows better results with support of non-parametric tests, LMoment Ratio Diagrams (LMRD) which is an additional way to measure goodness of fit to supports the claims. Log Pearsons-3 distribution are used globally for flood forecasting.

\section{REFERENCES}

1. Cunnane, C. (1989). "Statistical distributions for flood frequency Analysis". Operational Hydrology Report No. 33, World Meteorological Organization.

2. Georgakakos, K.P., (1986). A generalized stochastic hydro meteorological model for flood and flashflood forecasting, Part 1: Formulation. Journal of Water Resources Research 22(13), 20832095.

3. Haktanir, T., and Horlacher, H. B. (1993). Evaluation of various distributions for flood frequency analysis. Journal of Hydrological Sciences Journal, 38, 15-32.

4. Hosking, J. R. M. (1990). L-moments: Analysis and estimation of distributions using linear combinations of order statistics. Journal of Royal Statistical Society (Series B), 52, 105-124.

5. Hosking, J. R. M., \& Wallis, J. R. (1993). Some statistics useful in regional frequency analysis. Journal of Water Resources Research, 29, 271-281.

6. Hosking, J.R.M., Wallis, J.R. (1997). "Regional Frequency Analysis". Cambridge University Press, Cambridge.

7. Kjeldsen, T. R., Smithers, J. C., Schulze, R. E. (2002). Regional flood frequency analysis in the KwaZulu-Natal province, South Africa using the index-flood method. Hydrology.

8. Krzysztofowicz, R., (1993). A theory of flood warning systems. Journal of Water Resources Research 29(12), 3981-3994.

9. Krzysztofowicz, R., (2001). The case for probabilistic forecasting in hydrology. Hydrology 249(1-4), 2-9.

10. Krzysztofowicz, R., Davis, D.R., (1983). A methodology for evaluation of flood forecast-response systems, Part 2: Theory. Journal of Water Resources Research 19(6), 1431-1440. 23

11. Kumar, R., et. al. (2003). Development of regional flood frequency relationships using L-moments for Middle Ganga Plains Subzone 1(f) of India. Journal of Water Resources Management, 17, 243-257.

12. Lardet, P., Obled, Ch., (1994). Real-time flood forecasting using a stochastic rainfall generator. Hydrology 162, 391-408.

13. Saf, B. (2009). Regional flood frequency analysis using Lmoments for the west Mediterranean region of Turkey. Journal of Water Resources Management, 23, 531-551.

14. Solaiman, T.A., (2011). Uncertainty Estimation of Extreme Precipitations Under Climatic Change: A Non-Parametric Approach. PhD Thesis, Department of Civil and Environmental Engineering, The University of Western Ontario.
15. Stedinger, J.R., Vogel, R.M., Foufoula-Georgiou, E., (1992). Frequency analysis of extreme events. In: Maidment, D.R. (Ed.), Handbook of Hydrology. McGraw-Hill, New York.

16. Yue, S., \& Wang, C. Y. (2004). Possible regional probability distribution type of Canadian annual streamflow by L-moments. Journal of Water Resources Management, 18, 425-438.

\section{AUTHORS PROFILE}

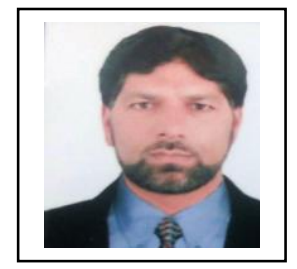

Dr. Khurshid Ahmad Bhat, Ph.D in Mathematical statistics, working as Senior Lecturer (vice Principal) in State Department of Education J\&K. published a good number of papers in international journals and attended many conferences and workshops in reputed institutes like IIT Rorkee, University of Delhi, ISI Kolkata.

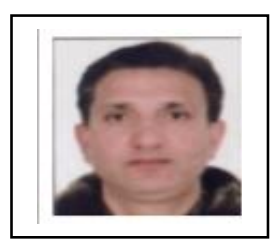

Dr. Bashir Ahmad, Ph.D. in Geology, working as lecturer in State Department of Education J\&K. published a good number of papers in international journals and attended many conferences of national and international repute.

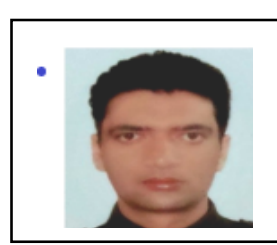

Dr. Akhter Alam, Ph.D in Geography, working as assistant professor Department of Geography in university of Kashmir, published a good number of papers in international journals of repute.

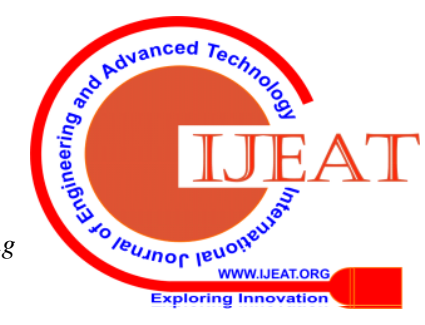

